\title{
EVALUACIÓN DE EVENTOS REPRODUCTIVOS Y ESTRÉS FISIOLÓGICO EN VERTEBRADOS SILVESTRES A PARTIR DE SUS EXCRETAS: EVOLUCIÓN DE UNA METODOLOGÍA NO INVASIVA
}

\author{
Carolina VALDESPINO ${ }^{1}$, Rodolfo MARTíneZ-MOTA², \\ Luis Manuel García-Feria ${ }^{3}$ \& Luis Enrique MARTíneZ-RoMERO 4 \\ 1, 2 Departamento de Biodiversidad y Ecología Animal. \\ 3 Departamento de Biología Evolutiva. Instituto de Ecología, A.C. \\ Km 2.5 Antigua Carretera a Coatepec No. 351. Xalapa, 91070 Ver., MÉXICO \\ ${ }^{4}$ Exhacienda San Bartolo Flor del Bosque. Carril a San Bartolo s/n \\ Amozoc de Mota, 72360 Puebla, Pue., MÉXICO \\ 1carolina.valdespino@inecol.edu.mex, ${ }^{2}$ rodolfo.martinez@posgrado.inecol.edu.mx, \\ 3 luis.garcia@posgrado.inecol.edu.mx,44azul_94@yahoo.com.mx
}

\begin{abstract}
RESUMEN
Este documento tiene como objetivo servir como referencia de términos y procesos asociados a una metodología no invasiva para el estudio de la fisiología de vertebrados silvestre, pero también de las transformaciones históricas que dicha metodología ha experimentado. Debido a la dificultad de su encuentro directo y su manipulación, las investigaciones de vertebrados silvestres requieren, muchas veces, de aproximaciones indirectas. Un recurso tradicionalmente empleado es la recolección de muestras fecales en el campo que permite definición de distribución, abundancia, dieta e infestación parasitaria de especies de interés. Más recientemente, tomado de prácticas veterinarias utilizadas en zoológicos y granjas, el uso de heces se ha adoptado para evaluar concentraciones de hormonas. Durante los últimos 10-15 años, la endocrinología de campo ha aportado información sobre los ciclos reproductivos, cambios estacionales en concentraciones hormonales, diferencias sexuales y de comportamiento asociadas a las hormonas, asociación entre posiciones jerárquicas, estrés y concentraciones hormonales con efectos sobre la reproducción y, aún, efectos de las actividades humanas sobre el bienestar de especies silvestres. Sin embargo, la investigación de las técnicas de laboratorio asociadas a esta disciplina durante los últimos 3 años, llama a tener precaución con su uso y enfatiza la validación previa, especie por especie. Dado que el avance de esta línea de investigación requiere de protocolos de análisis adecuados y de preguntas sólidas sobre ecología de campo, la colaboración creativa de expertos de ambas áreas (los técnicos de laboratorio y los ecólogos de fauna silvestre), sería una práctica pertinente en países como México donde los recursos humanos y capitales son limitados.

Palabras Clave: metodología no invasiva, endocrinología de campo, hormona, estrés, reproducción, vertebrado, excreta, muestra fecal, corticosteroides, testosterona, estradiol, progesterona.
\end{abstract}


Valdespino et al.: Metodologías no invasivas para estudiar vertebrados

\begin{abstract}
This aims to be a general reference document of terminology and processes associated with a noninvasive technique for the study of wildlife. But it will also summarize the historical changes that such technique has experienced throughout time. Due to the difficulties associated with their capture and manipulation, research on wild vertebrates has usually required indirect approaches. One such method is the collection of feces left by the target species on the ground, and its implementation has allowed determination of distributional ranges, abundances, diet composition and association with parasites. Adopted from veterinary and farm practices, measurement of hormone levels in feces has more recently originated the, so called, Field Endocrinology. During the last 10-15 years, this line of research has generated information on reproductive cycles, seasonal changes, behavioral associations and sex related differences in hormone levels, interactions between hierarchy status, stress and hormone levels and their effect on reproductive success and, finally, evaluation of human disturbance on animal physiology. During the last three years, however, research on the lab techniques associated with this discipline has evidenced a series of confounds resulting from sample manipulation. Since this type of research requires of both, good assay protocols as well as interesting ecological questions, creative collaboration between lab technicians and animal ecologists is urgent in countries like Mexico, where financial resources designated to investigation are so scarce.
\end{abstract}

Key Words: non-invasive method, field endocrinology, hormone, stress, reproduction, vertebrate, feces, fecal sample, corticosteroids, testosterone, estradiol, progesterone.

\title{
¿Por qué las excretas?
}

Uno de los recursos más apreciados por cualquier investigador interesado en el estudio de vertebrados, que no lo realice en las amplias sabanas africanas o en ambientes similares, o que no esté dedicado al estudio de especies diurnas (y aún muchas veces en estos casos), es el excremento de sus organismos de interés (Putman 1984). Investigaciones planeadas con el objetivo de medir esfuerzos de muestreo han demostrado que, por razones de escala tan solo, la obtención de un tamaño de muestra equivalente de organismos vertebrados requiere un esfuerzo de muestreo substancial y en general inalcanzablemente mayor que cuando el sujeto de trabajo es un organismo invertebrado (Lawton 1998). Este problema se incrementa aún más debido a los tamaños poblacionales reducidos y las áreas extensas en las que los vertebrados llevan a cabo sus actividades y, en el caso de los mamíferos, también por sus hábitos nocturnos y crípticos (Wilson \& Delahay 2001). Es por estas razones que las excretas producidas por las especies de interés son un recurso que permite incrementar tamaños muestrales y su recolección se ha convertido ya en una práctica documentada, admitida y utilizada de manera tradicional (Bookhout 1996).

Aprovechando la posibilidad de identificar el excremento de diferentes especies con base en su forma y tamaño (Halfpenny \& Biesiot 1986, McDougall 1992, Aranda 2000, Menkhorst \& Knight 2001, Elbroch 2003, Sánchez-Rojas et al. 2004, sin embargo véase también Paxinos et al. 1997 y Davison et al. 2002), se han descrito aspectos diversos de la ecología de vertebrados. La búsqueda y recolección de excretas en un área determinada, o a lo largo de un transecto, han permitido 
estimar tamaños poblacionales, abundancias, ámbitos hogareños y uso de hábitat de una especie determinada (Davis \& Winstead 1980, Ezcurra \& Gallina 1981, Mandujano \& Gallina 1995, Lancia et al. 1996, Litvaitis et al. 1996, Sánchez-Rojas \& Gallina 2000, Pérez-Mejía et al. 2004, Ortiz-Martínez et al. 2005) pero también la distribución y estructura de comunidades de mamíferos (Ray \& Sunquist 2001). Además, ha hecho posible el análisis de hábitos alimenticios y de la calidad de la dieta (Korschgen 1980, Cooperrider 1986, Mills 1996, Buenrostro et al. 2004) y el examen físico, microbiológico y químico ha proporcionado información sobre infestación parasitaria (Phillips \& Scheck 1991), evaluación de la flora bacteriana (Hirayama et al. 1989) y de exposición a policlorobifenilos (PCB) y a pesticidas (Mason \& Ratford 1994).

Un uso más de las excretas, que durante mucho tiempo estuvo limitado a las rutinas de manejo en parques zoológicos, principalmente americanos y europeos (Loskutoff et al. 1983, Lasley 1985), es la determinación del estado reproductivo de un organismo (Lasley \& Kirkpatrick 1991, Heistermann et al. 1995, Peter et al. 1996) y del estrés fisiológico que podría experimentar debido al manejo y prácticas de mantenimiento (Carlstead et al. 1993, Wielebnowski et al. 2000, Brousset Hernández-Jáuregui et al. 2005).

\section{La Fisiología reproductiva y los programas de reproducción en cautiverio}

En los zoológicos, el acomodo de los animales dentro de los albergues y los intercambios con otras instituciones depende, en gran medida, de la capacidad reproductiva de los animales con que se cuenta. La determinación de la madurez sexual y la fertilidad son necesarias en la planeación del establecimiento de parejas reproductoras; la separación de individuos que ya no son activos (si es necesaria); o para la reducción en la producción cuando hace falta espacio (Asa 1996, Ballou \& Foose 1996, Graham 1996, Hodges 1996, Wildt 1996).

Por otro lado las características de los encierros, la dieta, o la composición y tamaño de los grupos, pueden provocar la ausencia de la función reproductiva debido al estrés severo causado por la limitante de espacio y la cercanía de las personas; la falta de algún nutriente; o la presencia de coespecíficos (Ziegler et al. 1995, Carlstead 1996, Robinson 1996, Seidensticker \& Doherty 1996). Además, las prácticas propias del manejo de animales en cautiverio, como la contención, el transporte, la anestesia y las cirugías, también provocan estrés (Broom 1988, Nogueira \& Silva 1997, Dobson \& Smith 2000).

Debido a que la función reproductiva y las reacciones de estrés se asocian con cambios hormonales, el análisis de muestras de sangre es un método efectivo para lograr un seguimiento del estado reproductivo y del grado de estrés de los animales en estudio (Lasley \& Kirkpatrick 1991, Harper \& Austad 2000). Sin embargo, la obtención de muestras de sangre generalmente va precedida de la captura e 
inmovilización de los animales, lo que les provoca estrés, precisamente, y una modificación no deseable en las concentraciones de las hormonas relacionadas con la reproducción y, obviamente, con el estrés. Esto ha motivado la búsqueda de métodos alternativos, conocidos como métodos no-invasivos, que hagan posible llevar a cabo estudios y/o evaluaciones sin provocar cambios no deseados en la fisiología de los organismos de interés. La evaluación de hormonas esteroides en excretas ha hecho posible tales objetivos (Heistermann et al. 1995, Peter et al. 1996, von der Ohe \& Servheen 2002). Esta metodología estuvo enfocada, en primera instancia, a la detección de preñez (Safar-Hermann et al. 1987); la evaluación del potencial reproductivo (Lasley \& Kirkpatrick 1991), y el sexado en aves monomórficas (Bercovitz et al. 1978) en cautiverio.

Estos métodos de estudio de la reproducción y el estrés, de interés en colecciones de animales en cautiverio, han resultado aplicables a la evaluación de estas variables en poblaciones silvestres de vertebrados y, por tanto, su adopción ha sido un paso casi natural (Lasley \& Kirkpatrick 1991, Heistermann et al. 1995).

\section{Hormonas esteroides}

Las hormonas son mensajeros químicos secretados por glándulas endocrinas (Lombardi 1998) que actúan sobre un órgano blanco, provocando cambios fisiológicos y en el comportamiento de un individuo. Por su origen las hormonas que intervienen en los procesos reproductivos y de alarma pueden ser hormonas de tipo proteínico o peptídico, como la hormona luteotrófica (LH), la hormona folículo estimulante (FSH) y la hormona adrenocorticotrófica (ACTH) y hormonas de tipo esteroide (Nelson 2000).

Las hormonas esteroides son compuestos de naturaleza lipídica, no saponificables, y poco solubles en agua, caracterizadas por tener una estructura cíclica y saturada de 17 átomos de carbono (ciclopentanoperhidrofenantreno). Estos compuestos son sintetizados y secretados por las gónadas y las adrenales, principalmente (Nelson 2000). Las hormonas esteroides producidos por estas estructuras incluyen a:

1. Los esteroides sexuales como la testosterona, la progesterona y los estrógenos (uno de los cuáles es el estradiol), producidos principalmente por las gónadas, y

2. Los corticosteroides como los mineralocorticoides y los glucocorticoides, producidos por las adrenales (Norman \& Litwack 1997, Lombardi 1998).

\section{La Reproducción}

La transición de un individuo del estado no reproductivo al reproductivo, al alcanzar la madurez sexual, o la que ocurre cada año al inicio de la temporada reproductiva, es inducida por factores ambientales epigenéticos (químicos, visuales, táctiles, sociales, térmicos) que son transducidos en la síntesis y secreción de hormonas (Nelson 2000). El hipotálamo es el centro nervioso del 
cerebro que coordina numerosas actividades en el resto del organismo. En el caso particular de la reproducción, ante condiciones ambientales (clima, recursos, luz) y/o sociales (presencia de individuos del otro sexo) favorables activa el llamado eje hipotálamo-hipófisis-gónadas promoviendo el inicio de la reproducción (Bronson \& Heideman 1994). El hipotálamo estimula a la glándula hipófisis a liberar hormonas gonadotróficas (FSH y LH) que actúan directamente sobre las gónadas regulando la gametogénesis y la síntesis y secreción de hormonas esteroides (Nelson 2000).

En los ovarios de vertebrados vivíparos, la FSH regula el desarrollo folicular, y en los de vertebrados ovovivíparos, la vitelogénesis. En ambos la FSH promueve la síntesis y secreción de estrógenos como el estradiol (Lance \& Callard 1969, Licht 1984). En los testículos en cambio, la FSH regula fases de la espermatogénesis (Podestá \& Rivarola 1974, Temple 1974). En los ovarios la LH regula la fase lútea y la producción de progestágenos como la progesterona y en los testículos regula la síntesis de andrógenos como la testosterona (Lance \& Callard 1969, Podestá \& Rivarola 1974, Temple 1974, Licht 1984).

Los estrógenos son los compuestos asociados con la estimulación de la actividad reproductiva en hembras y determinan el fenotipo femenino mientras que la progesterona mantiene la gestación en vertebrados vivíparos (Johnson \& van Tienhoven 1980). Mientras tanto la testosterona está principalmente involucrada en el mantenimiento de caracteres sexuales masculinos, y liberada al torrente sanguíneo, actúa promoviendo el comportamiento de apareamiento masculino (Ramenofsky 1984).

A pesar de estas funciones aparentemente disociadas entre hembras y machos, los esteroides sexuales poseen estructura química similar y su biosíntesis está integrada de modo que pueden ser forma intermedia (prohormona) en la ruta metabólica hacia alguno otro (Griffin \& Ojeda 1988, Nelson 2000). La pregnenolona, hormona precursora de la progesterona es convertida en andrógenos (uno de los cuáles es la testosterona), y éstos en estrógenos tanto en los ovarios como en los testículos. De este modo los dos sexos difieren en las concentraciones de sus esteroides sexuales, pero tanto estrógenos, como progesterona y testosterona pueden encontrarse en la circulación sanguínea de hembras y machos de una especie (Lombardi 1998, Nelson 2000).

\section{Comportamiento y esteroides sexuales}

Los esteroides sexuales tienen un efecto sobre el comportamiento de un organismo porque una vez liberados al torrente sanguíneo llegan a células sensoriales, cerebrales o motoras y provocan cambios en su funcionamiento lo que facilita el desempeño de conductas (Beach 1976, Nelson 2000). Por ejemplo, en aves, los estrógenos promueven la conducta de nidificación (Farner \& Wingfield 1980) y 
en los cánidos, la receptividad durante el celo (Asa 1997, Valdespino et al. 2002). La testosterona, en cambio, está relacionada con agresión asociada a la reproducción (p. ej., defensa de territorio o resguardo de la pareja contra otros machos; Wingfield \& Marler 1988). En este sentido, por ejemplo, la conducta de cuidado paternal en machos, requiere que las concentraciones de testosterona disminuyan para que la agresión desaparezca y el macho no ataque a las crías (Farner \& Wingfield 1980, Hegner \& Wingfield 1987).

Por lo tanto, dado que los esteroides sexuales se liberan al torrente sanguíneo, la obtención de una muestra de sangre seguida de métodos analíticos apropiados permitirá conocer las concentraciones de esteroides de un individuo en un momento determinado. Al mismo tiempo, un seguimiento longitudinal de los cambios de concentraciones de esteroides en sangre (perfil hormonal característico de hembras y machos) a lo largo del tiempo, aunado al registro de su comportamiento, permite la definición de concentraciones características de diferentes estados de la vida reproductiva de un animal (Beach 1976, Brown 1985, Ketterson et al. 1991, Lasley \& Kirkpatrick 1991, Ketterson \& Nolan-Jr 1992, Reburn \& Wynne-Edwards 1999, Wynne-Edwards \& Reburn 2000).

\section{Estrés Fisiológico}

Cuando un animal percibe un estímulo como "estresante" (estímulo nocivo que provoca temor, ansiedad o inquietud), ocurren cambios fisiológicos en su organismo para enfrentar el problema (Wingfield et al. 1997). Estos cambios son resultado de la liberación de hormonas esteroides de la corteza adrenal (Nelson 2000, Romero 2004). Al igual que en el caso del inicio de la actividad reproductiva que responde a estímulos ambientales favorables, las respuestas fisiológicas al estrés se inician con la percepción del estímulo nocivo por el hipotálamo. Éste estimula al sistema simpático que libera norepinefrina y epinefrina (adrenalina), las cuáles promueven un incremento en la actividad motora, el ritmo cardiaco y la energía a través de la glicólisis y la lipólisis. Esta respuesta inmediata (en segundos) tiene la finalidad de huir del o enfrentar al agente estresante (Knol 1991, Nelson 2000). En el mediano plazo (2-10 minutos), se activa el eje hipotálamo-hipófisis-adrenales. En este caso, el hipotálamo estimula a la glándula hipófisis a liberar hormonas adrenocorticotrópicas $(\mathrm{ACTH})$, que llegan a la corteza de las glándulas adrenales y promueven la liberación de glucocorticoides al torrente sanguíneo (Knol 1991, Herman \& Cullinan 1997, Nelson 2000).

Los glucocorticoides producidos pueden ser el cortisol, en peces y la mayoría de los mamíferos; la corticosterona, en anfibios, aves, reptiles y roedores; o una combinación de ambos, en marsupiales, liebres, ardillas, ungulados y primates (Stratakis \& Chrousos 1995, Romero 2004). Los glucocorticoides promueven la glucogenólisis, proceso por el cual se libera glucosa al torrente sanguíneo permitiendo su captación por los músculos, incrementando por ejemplo el tono cardiovascular. Además los glucocorticoides 
estimulan la función inmune y agudizan el aprendizaje, inhiben la conducta y función reproductivas y disminuyen el apetito. En conjunto estos cambios, en respuesta a los factores estresantes, permiten el sostenimiento de la respuesta inicial de huída o el enfrentamiento por períodos aún más prolongados (Axelrod \& Reisine 1984). La cantidad en que se incrementan los glucocorticoides respecto de sus concentraciones basales puede indicar la severidad del factor estresante (Hennessy et al. 1979). Una vez que el factor de peligro ha desaparecido, las concentraciones de glucocorticoides regresan de manera gradual (minutos a horas) a su concentración basal.

\section{Estrés y Reproducción}

La respuesta fisiológica al estrés momentáneo (estrés agudo) es considerada adaptativa porque dirige la energía del organismo a las funciones que maximizan su sobrevivencia y pospone las que no son necesarias en el momento (von Holst 1998). Sin embargo, si el factor estresante no desaparece (estrés crónico) y los glucocorticoides permanecen elevados por más de algunos días, se provoca una amplia variedad de consecuencias negativas (Sapolsky 1992). Estos efectos negativos aparecen como patologías en el largo plazo e incluyen la depresión del sistema inmune, favoreciendo un incremento en la susceptibilidad a enfermedades (Munck et al. 1984); la inhibición de la reproducción (Ferin 1999, Wingfield \& Sapolsky, 2003); la pérdida de tejido muscular (aún el cardíaco) y el decremento en la capacidad de aprendizaje (McEwen \& Sapolsky, 1995, Ohl \& Fuchs, 1999]

De particular interés para este ensayo es la inhibición de la reproducción por estrés crónico debido a que la misma es resultado de la interferencia entre los dos ejes descritos de regulación por parte del hipotálamo, el que conecta a la hipófisis con las adrenales y el que lo hace con las gónadas. La secreción de hormonas hipotalámicas e hipofisiarias que promueven la reacción de estrés afectan la ritmicidad de las que regulan los ciclos reproductivos y, por ende, las concentraciones de estrógenos en las hembras (Dobson \& Smith 2000) y de andrógenos como la testosterona en los machos (Cummings et al. 1983).

La relación entre estas dos redes endocrinas hacen posible el planteamiento de proyectos sobre la ecología de vertebrados en que se respondan preguntas sobre el efecto de factores estresantes diversos sobre el potencial reproductivo de animales en cautiverio o en estado silvestre (Reeder \& Kramer 2005).

\section{Excreción de esteroides y sus metabolitos}

Una vez que han llegado a las células "blanco" y afectado la fisiología y el comportamiento de un organismo, los esteroides pierden su capacidad de acción notablemente (Gower 1979, Aranyi 1983, Walter \& Hongwei 2003, McNabb 2004, Landsman \& Waxman 2005). Sin embargo el órgano principal de desactivación y catabolismo de los esteroides (al igual que otras hormonas) es el hígado (Siiteri 
1981). Los esteroides parentales o metabolizados (hidroxilados, reducidos, sulfatados o glucorónidos), libres y/o unidos a proteínas acarreadoras, pasan entonces al intestino emulsificados en los ácidos biliares, lo cual permite que sean eliminados en la materia fecal (Norman \& Litwack 1987, Cockrem \& Rounce 1994). Otras porciones de esteroides son eliminadas en la orina después de ser filtradas en los riñones (Sturkie 1968, Gower 1979). Las hormonas esteroides se eliminan como tales o como metabolitos y su tasa de excreción y metabolismo varía de acuerdo con la fisiología de cada especie (Adlercreutz \& Martín 1980).

Es justo esta ruta fisiológica la que permite determinar el funcionamiento gonádico y adrenal de un organismo por métodos no invasivos. Obteniendo excretas de los organismos de interés y evaluando en ellas las concentraciones de esteroides parentales o metabolitos, es posible conocer el estado de un organismo sin necesidad de capturarlo para tomar de él una muestra de sangre (Heistermann et al. 1995, von der Ohe \& Servheen 2002). De hecho, en la actualidad, existen suficientes datos de numerosas especies, en apoyo de la posibilidad de generalizar que los perfiles hormonales obtenidos evaluando esteroides fecales, reflejan la actividad gonádica y adrenal reflejando el estado endocrino de un individuo (Lasley \& Kirkpatrick 1991).

\section{Beneficios de medir hormonas esteroides en excretas}

El beneficio mayor de emplear excretas para hacer seguimientos de perfiles hormonales es que el procedimiento de colecta puede extenderse por períodos largos sin necesidad de manipular - estresar- a los animales, lo cual es muy conveniente cuando los eventos que desean estudiarse son poco frecuentes, tienen lugar por períodos prolongados, o la disponibilidad de sangre que se puede colectar es limitada (Lasley \& Kirkpatrick 1991, Harper \& Austad, 2000, Millspaugh et al, 2001, 2002, Möstl \& Palme, 2002, Touma et al, 2003, Wasser et al., 2000).

Otra ventaja tiene que ver con el hecho de que la concentración de metabolitos es, en general, de 2 a 4 órdenes de magnitud mayor que la de los esteroides parentales en sangre. Por lo tanto, permiten el uso de kits o estuches comerciales para efectuar mediciones manuales o automatizadas (Lasley \& Kirkpatrick 1991).

Por otro lado, la secreción de hormonas por parte de las glándulas es generalmente de naturaleza pulsátil con lo cuál, a lo largo del día, muestras de sangre reportarán variación en la concentración. Sin embargo, las cantidades que se eliminan en las excretas corresponden a la producción acumulada a través del tiempo con lo cuál se elimina esta variación circadica (Harper \& Austad 2000, Goyman 2005).

\section{Aplicación especial: el sexado de animales}

Hasta el $30 \%$ de las especies de aves y muchos reptiles carecen de dimorfismo sexual (Bercovitz et al. 1978). Esto es un problema grave para el manejo de especies 
que son sujetos de programas de reproducción en cautiverio porque el desconocimiento del sexo de los individuos impide un arreglo inmediato de los animales en parejas reproductoras.

Las técnicas de sexado que se han empleado en estos casos incluyen las mediciones anatómicas, la laparoscopia, la identificación cromosómica y el pesado del núcleo de las células sanguíneas (Bercovitz et al. 1978). Una técnica extra, basada en la medición de esteroides sexuales, se probó por primera vez en el dragón de Komodo (Judd et al. 1977). En este caso, utilizando como base las diferencias en la cantidad de testosterona circulante entre machos y hembras se logró la identificación correcta del sexo, establecido previamente por ultrasonido a través de la pared abdominal. Este método podría ser empleado en otras especies, pero el riesgo por manejo de los animales para obtener la muestra de sangre es alto.

La evaluación de las concentraciones de hormonas esteroides y/o sus metabolitos en excretas ha demostrado ser una técnica de utilidad que se aplica ampliamente con este fin en colecciones de instituciones zoológicas (Bercovitz et al.1978, Lee et al. 1990, Tell \& Lasley 1991). Las evaluaciones iniciales de esta técnica se hicieron en especies de aves dimórficas y los ensayos permitieron establecer que el uso del cociente entre la concentración de un estrógeno (el estradiol) y de testosterona $\left(\mathrm{E}_{2} / \mathrm{T}\right)$ de cada muestra de excremento evaluada, ofrecía una diferenciación más clara del sexo del donante que la medición de cada esteroide por separado (asumiendo testosterona elevada para machos y estradiol elevado para hembras). Esto, porque los valores de las hormonas de machos y hembras de manera, independiente mostraban sobrelapamiento. En contraste, cocientes promedio de $\mathrm{E}_{2} / \mathrm{T}$ elevados corresponden a hembras y cocientes bajos corresponden a machos (Bercovitz et al. 1978). La determinación del cociente $\mathrm{E}_{2} / \mathrm{T}$ de muestras de excretas se ha efectuado posteriormente en diferentes especies de aves monomórficas, comprobándose su utilidad en Psitácidos (Bercovitz et al. 1978, Bishop \& Hall 1991), pero no en Crácidos (Czekala \& Lasley 1977, Bercovitz et al. 1978).

$\mathrm{Su}$ adaptación al sexado de excretas colectadas en campo permitirían una evaluación no sólo de densidades o abundancias poblacionales de la especie de interés, sino incluso la determinación de proporciones sexuales en estudios demográficos (Cockrem \& Seddon 1994).

\section{Vínculo entre zoológicos y fauna silvestre}

El empleo de excretas para evaluación de concentraciones hormonales es, en la actualidad, una práctica extendida en zoológicos en donde, como se mencionó previamente, se determina preñez (cebra, yak, búfalo, íbice e hipopótamo: SafarHermann et al. 1987; caballo: Schwarzenberger et al. 1991; venado cola blanca: Mercado-Reyes et al. 2001); ciclos reproductivos (codorniz: Bishop \& Hall 1991; grisón, nutria, guepardo, alce, lobo de crin y tigre: Gross 1992: Monfort et al. 1993; 
tigre, león, guepardo, leopardo, lince: Graham et al. 1995; orix: Shaw et al. 1995; perro salvaje: Monfort et al. 1997; lobo de crin: Velloso et al. 1998; zorro fennec: Valdespino et al. 2002); anomalías reproductivas (ninfa: Tell \& Lasley 1991; guepardo: Czekala et al. 1994); sexo en especies monomórficas (19 especies de aves: Bercovitz et al. 1978); efectos de la aplicación de anestésicos (jaguar, puma, ocelote y yaguarundí: Nogueira \& Silva 1997); bienestar de los animales en los albergues (gato, leopardo, jaguar: Carlstead et al. 1993; leopardo: Wielebnowski et al. 2002) o incluso para establecer estándares de utilidad en estudios de la especie en vida libre (lobo de crin: Velloso et al. 1998).

Los procedimientos empleados en la solubilización de los metabolitos y las hormonas parentales contenidos en las excretas, y su posterior medición, han sido investigados ampliamente desde los inicios del empleo de estos métodos. En 1992, inclusive, tuvo lugar el Primer Simposio Internacional sobre Monitoreo de Esteroides Fecales en Animales de Zoológico (Schaftenaar et al. 1992) en donde se presentaron y discutieron aspectos como:

1. El efecto que la presencia de fibra en la dieta tiene sobre las concentraciones hormonales que se miden y la recomendación del uso de otros compuestos que sirvan como un índice (Wasser et al. 1992).

2. La imposibilidad de medir algunos esteroides en excretas de algunas especies (p. ej. ratones), dado que la mayor parte de su eliminación ocurre a través de la orina (Möstl 1992).

3. El efecto de la variación del contenido de la dieta en la varianza de las concentraciones medidas por períodos largos (Gross 1992).

4. Las diferencias de escala en las concentraciones de esteroides en diferentes especies (Buiter et al. 1992).

5. La factibilidad de muestreo y determinación de diferentes procesos reproductivos en fauna silvestre (Kirkpatrick et al. 1992).

La adopción directa de estas técnicas a estudios de animales que pueden ser observados directamente por los investigadores en estado silvestre o endocrinología de campo (Field Endocrinology, sensu Wingfield et al. 1997) brinda la posibilidad de describir ciclos reproductivos (papión: Wasser et al. 1991; caballo y bisonte: Kirkpatrick et al. 1992; muriquí: Strier \& Ziegler 1997; mono araña: Campbell et al. 2001); cambios estacionales en las concentraciones hormonales (ganso: Hirschenhauser et al. 1999; muriquí: Strier et al. 1999); diferencias sexuales y de comportamiento asociadas a concentraciones de testosterona (hiena: Dloniak et al. 2004); diferencias sexuales y estacionales en las concentraciones de cortisol (muriquí: Strier et al. 1999; elefante: Foley et al. 2001); tamaño óptimo de grupo y concentración de cortisol como medida de estrés (lémur: Pride 2005); y relación de la posición jerárquica con las concentraciones de cortisol como medida de estrés (tití 
cabeza de algodón: Ziegler et al. 1995; muriquí: Strier et al. 1999; suricata, perro salvaje y lobo gris: Creel, 2005).

Dado el efecto que el estrés tiene sobre el bienestar, la salud y la reproducción de un organismo, la determinación del estrés fisiológico se ha convertido en un objetivo primordial en la conservación de las especies (Romero 2004). Con este objetivo se han medido concentraciones de corticosteroides como un método para cuantificar el efecto del uso de vehículos motorizados para la nieve sobre lobos y alces (Creel et al. 2002); las prácticas de cacería sobre pumas (Harlow et al. 1992); ciervos (Bateson \& Bradshaw 1997) y wapitis (Ball et al. 1997); el ruido y el efecto de la tala de árboles sobre el búho moteado (Wasser et al. 1997; Tempel \& Gutierrez 2003); y aun de las prácticas de conservación mismas, por ejemplo el efecto de la translocación de hienas (Goyman et al. 1999) y guepardos (Terio et al. 1999) hacia otros sitios para incrementar sus posibilidades de sobrevivencia.

El progreso en estas metodologías ha, incluso, sugerido medir la dinámica y salud de ecosistemas completos en los que se han reintroducido o que están siendo recolonizados por especies depredadoras. En estos casos se determinan incidencias de gestación en las especies presa presentes en el área por medio de la medición de progestágenos fecales (Berger et al. 1999).

El auge alcanzado y la importancia de los estudios en este campo condujeron a la organización del Simposio "Stress in Nature: Impact on Physiology, Ecology, and Natural History" dentro de la $83^{\mathrm{a}}$ reunión anual de la American Society of Mammalogists. Esta reunión tuvo el objetivo de familiarizar a los mastozoólogos con los cambios fisiológicos inherentes a la respuesta al estrés, las consecuencias adaptativas y no adaptativas del mismo, la interacción entre el estrés y la ecología, el ambiente social y la historia natural de un organismo, y también con los métodos disponibles para medir estrés (Reeder \& Kramer 2005).

\section{Precaución: los hallazgos recientes}

El entusiasmo inicial generado por la posibilidad de aplicar estas metodologías al estudio de aspectos eco-fisiológicos de animales en estado silvestre ha permitido un avance considerable en el conocimiento de algunos aspectos de la ecología de especies. Sin embargo como resultado de la investigación de las técnicas de laboratorio empleadas en este tipo de estudios durante casi 20 años, se ha hecho un llamado a la precaución en las generalizaciones e incluso en la aplicación de las metodologías mismas. Revisiones efectuadas durante los últimos 2 años indican que algunas tendencias optimistas del pasado deben frenarse. Algunas evaluaciones de las metodologías han sido francamente negativas e incluso han hecho dudar de la validez de los avances logrados hasta ahora (Buchanan \& Goldsmith 2004).

Para algunos autores la eliminación del comportamiento pulsátil de la secreción de algunas hormonas a lo largo del día que se logra al evaluar 
concentraciones de hormonas fecales, es un punto a favor del uso de excretas (Goyman 2005). Sin embargo, las críticas indican que las excretas expresan cantidades promedio de hormonas a lo largo de un período desconocido de tiempo, lo que reduce su sensibilidad en expresar cambios fisiológicos en comparación con las muestras sanguíneas (Shirtcliff et al. 2002). Es importante, en este caso, conocer esta limitante, pero en preguntas sobre cambios a largo plazo la utilidad de las excretas es indiscutible.

Por otro lado, el entusiasmo despertado por este tipo de trabajos ha llevado a la evaluación de concentraciones hormonales en excretas usando kits o estuches comerciales $\sin$ efectuar las validaciones necesarias. Estas validaciones eran reportadas en las publicaciones tempranas dentro del cuerpo de un artículo, pero en fechas recientes dejaron de incluirse porque los laboratorios de investigación serios las llevan a cabo de manera rutinaria y los editores obviaban su realización por lo cuál no la solicitaban en los manuscritos. Los investigadores nuevos, interesados en aplicar estas técnicas a sus estudios no comprenden la importancia real de estas validaciones e inician sus proyectos sin comprobar si lo que están evaluando realmente es lo que reportan (Buchanan \& Goldsmith 2004). Estas validaciones son, de modo simplificado, la comprobación de que los anticuerpos que se usan están efectivamente midiendo la hormona de interés; la sensibilidad para reportar ausencia total de la hormona y el error asociado a las evaluaciones. Una descripción técnica de estos análisis se puede revisar en Lasley \& Kirkpatrick 1991, Ezan 1997, Wasser et al. 2000, Heistermann et al. 2006.

En 1991, Lasley y Kirkpatrick indicaban que los metabolitos de esteroides al ser excretados en la orina o las heces permanecían de manera estable por un tiempo prolongado y que, por lo tanto, las excretas que contenían estos metabolitos podían colectarse y preservarse congeladas indefinidamente. Sin embargo recientemente se ha enfatizado en el cuidado que debe tenerse con la degradación de los esteroides fecales después de que las excretas han sido evacuadas debido a que, en cuestión de horas, bacterias y hongos comienzan a metabolizarlos (Wasser et al. 1988). Ante esto, el uso de etanol o de azida de sodio ha demostrado ser de utilidad para inhibir durante unas horas dicha biodegradación a temperatura ambiente (Wasser et al. 1998). Por lo tanto, conforme la muestra fecal se descompone física y biológicamente, la concentración de los metabolitos se reduce, pero la concentración de la hormona parental aumenta. Dependiendo del tipo de kit o estuche utilizado, si los esteroides de una muestra se valoran a diferentes tiempos, podría obtenerse un incremento del contenido de los mismos conforme el tiempo de almacenamiento aumenta cuando se empleé un kit o estuche poco específico (p. ej. andrógenos, Wasser et al. 2000), pero una disminución si se utiliza uno muy específico (p. ej. testosterona, Wasser et al. 1988). Es decir que, muestras almacenadas por más tiempo (las primeras de un estudio), arrojarían resultados que no tendría relación alguna con 
variables ecológicas o fisiológicas. Recientemente se ha constatado que las muestras que se conservan a temperatura ambiente sufren esta alteración en mayor grado que aquellas que se mantienen en congelación a $-20^{\circ} \mathrm{C}$, aún cuando ambas sufren este proceso (Kahn et al. 2002). Por tal motivo se recomienda que el mantenimiento de las excretas en congelación antes de efectuar las evaluaciones no exceda los 4 meses ya que después de ese tiempo los metabolitos parecen deteriorarse irreversiblemente (Kahn et al. 2002).

Se ha sugerido, ante esto, la investigación de los cambios que las concentraciones de esteroides tienen en los extractos de excretas a lo largo del tiempo con el fin de determinar qué tipo de kit o estuche utilizar, qué metabolitos evaluar, qué tiempo mantener las muestras en congelación como máximo antes de efectuar los análisis o qué otro tipo de almacenaje emplear. Estos análisis deberían llevarse a cabo para cada especie animal con la que se esté efectuando un estudio. Las investigaciones en este sentido han dado ya inicio aportando detalles de los métodos óptimos de almacenamiento y evaluación para diferentes esteroides (Lynch et al. 2003). Sin embargo, aunque son importantes, este tipo de investigaciones no permiten abordar de manera mediata la pregunta ecológica que generalmente motiva un trabajo, y también requieren de varios miles de pesos previos a la aportación en el conocimiento de la biología de las especies de interés.

Aún cuando la luz infrarroja ha empezado a brindar resultados increíbles de la vida de animales nocturnos, la posibilidad de llevar a cabo observaciones directas del comportamiento de vertebrados en su hábitat natural se restringe a aquellas especies de costumbres diurnas y, entre mamíferos, de vida generalmente gregaria. Aún así, hay especies animales a las cuáles es imposible seguir a través del campo con el fin de colectar muestras de excretas. Desde el documento germinal de Lasley y Kirkpatrick en 1991 se hacía la sugerencia de que los estudios de evaluaciones poblacionales de fauna silvestre que se efectúan tradicionalmente a través del conteo de excretas, podrían beneficiarse de estas metodologías no invasivas. La determinación de la proporción sexual; la de juveniles respecto de adultos; la incidencia de preñez entre las hembras de un grupo y la determinación de presencia o ausencia de estrés fisiológico de poblaciones en estado silvestre sería de suma utilidad para el conocimiento de especies diversas.

Inicio de estudios en el Instituto de Ecología A. C.

Una de las situaciones que muchos ecólogos de fauna silvestre críptica tienen que enfrentar es la recolección de excretas de antigüedad desconocida producidas por individuos que no son directamente observados (Buchanan \& Goldsmith 2004). De acuerdo con Lasley y Kirkpatrick (1991), las concentraciones de hormonas fecales son relativamente estables por períodos prolongados y, por tanto, sería potencialmente posible definir estados fisiológicos de individuos de una especie 
recolectando excretas en el campo. Con fines de obtener parámetros válidos para ecólogos que estudian poblaciones de venado cola blanca (Odocoileus virginianus) en vida libre, Martínez-Romero (2004) llevó a cabo un seguimiento de excretas producidas por individuos en cautiverio y mantenidas a la intemperie hasta por 5 días. De estas muestras se eligieron pellets al azar y se evaluaron progesterona, estradiol y testosterona desde el momento en que fueron producidas y a lo largo de diferentes "edades" hasta los 5 días de antigüedad. Se demostró que las concentraciones de los esteroides parentales disminuyen a diferentes tasas, con la progesterona disminuyendo más rápidamente $(80 \%$ a los 5 días) y el estradiol más lentamente (15\% a los 5 días) que la testosterona (Martínez-Romero 2004; MartínezRomero et al., datos no publicados). En este estudio se elaboró, en paralelo, un registro fotográfico de las excretas conforme pasaba el tiempo con el objetivo de brindar una referencia visual para ecólogos de campo. Se buscaba poder datar el tiempo desde la evacuación de las heces y extrapolar los resultados hasta los valores originales en las excretas. La calibración de estas dos metodologías podría ser de enorme utilidad en estudios de poblaciones de otras especies en vida libre.

En otros casos los animales pueden ser visibles para los investigadores y, quizás, el donador de las muestras recolectadas podría ser identificado (Wasser et al. 2000), este es el caso de las aves. Sin embargo muchas especies carecen de dimorfismo sexual (Bercovitz et al. 1978) que permita conocer el sexo del individuo de quien se obtiene una muestra, limitando las conclusiones que puedan tenerse. Tal es el caso del pavón (Oreophasis derbianus), especie endémica de México y de algunos bosques de niebla de Centroamérica y que se encuentra en peligro de extinción. La posibilidad de "sexar" las muestras brindaría evaluaciones de tamaños poblacionales por sexo en vida libre sin necesidad de capturar a los animales o de establecer parejas reproductoras en cautiverio sin esperar a que vocalicen durante la época reproductiva, que es otra forma de sexarlos (González-García 1984). Como los lazos de pareja requieren de tiempo, tener a las parejas ya establecidas antes de que inicie la época reproductiva garantiza mayor éxito de la nidada. García-Feria (2003) realizó un trabajo con animales en cautiverio los cuáles habían sido sexados previamente por laparoscopia. Efectuando mediciones de estradiol y testosterona tanto de hembras como de machos se encontró que el uso del cociente $\mathrm{E}_{2} / \mathrm{T}$ no permite determinar el sexo de un animal porque los valores se sobrelapan. Esto contrasta con los hallazgos efectuados en otras familias de aves (Bercovitz et al. 1978, Bishop \& Hall 1991). Sin embargo, la comparación de los valores de testosterona durante la época reproductiva sí son significativamente más elevadas en los machos que en las hembras. De este modo, en el caso del pavón, aún cuando pudieran obtenerse muestras de individuos conocidos para medir concentraciones hormonales, las preguntas correspondientes a cada sexo deberían responderse con otros métodos (García-Feria et al., datos no publicados).

Tradicionalmente se ha evaluado el efecto de la fragmentación de los bosques sobre la diversidad de especies (Wilcove et al. 1986, Myers 1988, Harris \& Silva- 
López 1992, Laurance 1997) o, para especies particulares sobre su diversidad genética (Allendorf \& Leary 1986, Lacy 1992). Sin embargo son pocos los estudios que evalúan el efecto de esta modificación del hábitat sobre la fisiología de organismos. En el 2004 Martínez-Mota reportó los resultados de un estudio en que puso a prueba la idea de que la fragmentación del hábitat puede ser un factor que estresa a los monos aulladores negros (Alouatta pigra), comúnmente citados como una especie capaz de habitar ambientes transformados (Wilcove et al. 1986). Por otro lado, aún cuando Sapolsky (1993) indicaba que el cortisol es el corticosteroide mayormente producido en primates $\mathrm{y}$, de hecho, todos las investigaciones realizadas en un inicio con muestras de sangre cuantificaron cortisol (mono ardilla: Terao et al. 1995; chimpancé: Whitten et al. 1998; tití: Ziegler et al. 1995, Norcross \& Newman 1999; macaco: Morgan et al. 2000), recientemente se ha reportado que, al parecer como una adaptación para eliminar sus efectos negativos, el cortisol se metaboliza rápidamente y su eliminación como hormona parental por vía fecal es reducida (Heisterman et al. 2006). Por tanto, el empleo de un kit específico para medir concentraciones de esta hormona en excretas puede dar resultados poco contundentes. Aún así, el trabajo de Martínez-Mota demuestra que los monos que viven en parches de bosques tienen concentraciones de cortisol fecal mayores que las tropas que viven en bosques conservados, lo que sugiere que, aún cuando los aulladores no son una especie que se extinga en el corto plazo, podrían estar sobreviviendo en condiciones fisiológicas que reduzcan su potencial reproductivo y su sobrevivencia en el largo plazo (Martínez-Mota et al., 2007).

Por otra parte, aprovechando otra de las "cualidades" de las excretas que es la de ser fuente de ADN del individuo que las produce debido a la eliminación en ellas de células de la pared intestinal (Kohn \& Wayne 1997), se está llevando a cabo la identificación, a nivel de especie, de excretas colectadas a lo largo de un año (Guillén y Valdespino, datos sin publicar). La finalidad de este trabajo es determinar la época reproductiva del zorro gris (Urocyon cinereoargenteus) en latitudes mexicanas en comparación con las poblaciones norteamericanas, ya que el fotoperíodo imperante en un sitio define el inicio de la misma (Bronson \& Heideman 1994). Las muestras identificadas por métodos moleculares como excretas de zorro serán evaluadas para esteroides sexuales con lo que se identificará el momento del estro y se describirán los perfiles hormonales a lo largo del año.

Estos cuatro estudios demuestran el potencial de las investigaciones en endocrinología de campo, que permitirían contestar preguntas a nivel individual o poblacional de gran interés tanto en ecología básica como de conservación de fauna silvestre.

\section{Estrategia para México}

Además de las precauciones descritas en la sección sobre problemas encontrados recientemente en la metodología de almacenaje y valoración de hormonas esteroides 
en las heces, los países en desarrollo tienen que enfrentar algunos obstáculos relacionados con la limitación de presupuesto. Por ejemplo, a pesar de que la difusión de conocimiento a través de la World Wide Web es grande, la llegada a nuestro país de los progresos y últimos hallazgos tiene un rezago debido a que los mismos se publican principalmente en revistas extranjeras. Los investigadores enfocados en este tema particular pueden estar suscritos a algunas de las revistas, pero la percolación hacia el resto de los investigadores, que quizás solo toquen el tema lateralmente, o a los estudiantes que podrían interesarse en él, ocurre muy lentamente. Por otro lado, las bibliotecas de instituciones académicas tienen suscripciones a revistas que tradicionalmente son requeridas masivamente por investigadores y estudiantes, pero las que están enfocadas a temas nuevos requieren tiempo para ser demandadas y que se justifique su adquisición.

Debido a que la discusión y divulgación progresiva de los avances metodológicos, se dan inicialmente a nivel de conferencias internacionales especializadas de costos generalmente prohibitivos, sólo sus participantes tienen la oportunidad de ir incorporando las mejoras en sus técnicas. Los demás usuarios potenciales tienen acceso a estos avances hasta que han sido publicados, lo cual puede tomar meses. Pero aún en ese momento, si se quedan sólo a nivel de revistas especializadas en técnicas de análisis de laboratorio, difícilmente llegarán hasta los ecólogos de campo, manejadores y biólogos de la conservación de vertebrados silvestres antes de que éstos hayan efectuado varios estudios analizando las muestras de sus organismos de interés con técnicas obsoletas. Esto es así porque tales publicaciones no forman parte de las colecciones de las bibliotecas (como se indicó arriba) o, en la mayoría de los casos, porque la discusión de qué cantidad de qué buffer, de qué $\mathrm{pH}$ o en qué proporciones añadirlo no es, en general, de interés para dichos profesionistas interesados preferentemente en el significado biológico de los resultados obtenidos.

Otro problema característico de aquellas áreas de investigación que surgen de la confluencia de dos que fueron independientes en su momento, es lo que podría llamarse el problema generacional. Los expertos en cada una de las áreas parentales siguen investigando y profundizando en el conocimiento particular de su línea, mientras que los nuevos híbridos proceden a explorar la posibilidades y limitantes del nuevo campo de trabajo. En este sentido la nueva disciplina es, de algún modo, más débil que sus predecesores porque aún no se conoce exactamente hacia dónde podrá encaminarse y, en términos generales, no tiene identidad propia y no se la ubica como perteneciente a una $u$ otra áreas antecesoras. Muchos investigadores tradicionales tienden a considerar esas combinaciones de temas de investigación como un "desprestigio" y es difícil ir abriendo campo a las nuevas áreas de estudio y el tipo de publicaciones.

De hecho, el control y los tamaños de muestra que pueden lograrse en el área de endocrinología biomédica, con animales de laboratorio (donde los estudios sobre 
endocrinología teórica se desarrollan más adecuadamente), son imposibles de conseguir en el caso de la endocrinología de campo. Esto es, aunque las excretas permiten incrementar el tamaño de muestra, los animales silvestres son más escasos y están más ampliamente distribuidos y encontrar sus excretas es un trabajo laborioso. La evaluación de propuestas de investigación en endocrinología de campo por fisiólogos de laboratorio, hecha con el rigor que requiere un trabajo llevado a cabo bajo condiciones controladas, frena más que ayuda el progreso del estudio de aspectos ecológicos de animales silvestres.

Por otro lado, lo incipiente de la endocrinología de campo en México provoca que, en un país con recursos limitados como el nuestro, sea difícil que un solo investigador o una sola institución cuente con los instrumentos y la infraestructura necesarios para llevar a cabo proyectos con dicho enfoque. Ante estas dos situaciones, un consejo para los ecólogos es oportuno, trabajar en colaboración cercana con endocrinólogos, químicos u otros profesionales en el área biomédica que mantengan una investigación constante de las técnicas de extracción, preservación y cuantificación de hormonas esteroides y que se mantengan actualizados en la literatura correspondiente. Esto hará posible que, aún con la producción actual explosiva de conocimiento en el extranjero, se utilicen procedimientos validados, ya publicados, para cada especie con la cuál el experto mexicano en ecología planteé proyectos con bases teóricas sólidas o con utilidad práctica.

Esta sería una forma de optimizar el tiempo de generación de conocimiento, empleando recursos humanos especializados en cada área y distribuyendo el dinero disponible en cada una de manera eficiente para constituir grupos enfocados en la endocrinología de campo. El trabajo coordinado de investigadores relacionados podría crear una punta generatriz de conocimiento que no solo permitiera avanzar en las preguntas de investigación más actual, sino en lograr el desarrollo intelectual de todo un grupo de trabajo. Bajo las condiciones actuales de desarrollo de nuestro país éste sería, quizás, el único modo de mantenerse a la vanguardia en el campo de la endocrinología de campo. En México varios equipos de trabajo han abordado esporádicamente temas relacionados con la medición de hormonas esteroides en excretas, muchos de éstos se han caracterizado por contar con participación interinstitucional, lo cual debería facilitar las colaboraciones futuras. Entre las instituciones que están trabajando actualmente en este campo se encuentran la Facultad de Medicina Veterinaria y Zootecnia de la Universidad Nacional Autónoma de México y de la Universidad Autónoma de Yucatán; los Departamentos de Biología y Biología de la Reproducción de la Universidad Autónoma Metropolitana, Unidad Iztapalapa; el Departamento de Fisiología, Biofísica y Neurociencias del CINVESTAV-IPN; el Instituto de Neuroetología de la Universidad Veracruzana; el Laboratorio de Neurofisiología de la Universidad Autónoma de Querétaro; la Unidad de Biología Experimental de la Universidad Autónoma de Zacatecas; la Facultad de 
Ciencias de la Universidad Autónoma de Baja California campus Ensenada y de la Universidad Autónoma del Estado de México y el Laboratorio de Reproducción del Zoológico de Chapultepec; el Laboratorio de Fisiología de la Reproducción del Centro de Investigaciones Fisiológicas de la Universidad de Tlaxcala y el Instituto de Psiquiatría de la Ciudad de México. Ejemplos de los trabajos producidos en estas instituciones incluyen: Montes-Pérez et al (1999), Ayala-Cano \& Martínez-Gallardo (2001), Mercado-Reyes et al. (2001), Ayala-Cano (2003), Soto (2004), Soto et al (2004), Brousset Hernández-Jáuregui et al. (2005), Pérez-García (2005), CerdaMolina et al y Soto-Mendoza (2006). Los investigadores que han intervenido en estos trabajos han formado a otros profesionales que, al mismo tiempo, han iniciado estudios por cuenta propia. Las especies estudiadas incluyen al lobo Mexicano, el venado cola blanca, el borrego cimarrón, el mono aullador, el mono araña, el pavón, el puma, el jaguar, el pecarí de collar y, probablemente, 2 o 3 más, pero no llegan a quince. Pero de estos trabajos muy pocos han logrado ser publicados en revistas indexadas debido, precisamente, a las problemáticas mencionadas.

Este ensayo tiene la finalidad de colocarnos a todos aquellos involucrados en la obtención de información fisiológica y/o endocrina de vertebrados silvestres en cautiverio o en vida libre en una posición crítica sobre los alcances de nuestro trabajo. Creemos que haría posible crear un grupo mexicano de investigación en endocrinología de campo:

1. Utilizar técnicas estandarizadas que nos permitan comparar resultados,

2. Compartir experiencias negativas,

3. Compartir evaluaciones puntuales de especies estudiadas, de modo que sirvan de referencia para otros estudios,

4. Mantenernos actualizados en las últimas metodologías,

5. Formar recursos humanos/profesionales en el campo.

Resulta una verdadera desgracia que siendo México un país tan diverso y con problemáticas en ecología, conservación y manejo tan variadas, no se estén llevando a cabo más estudios con más especies utilizando estos métodos.

\section{CONCLUSIONES}

El empleo de muestras fecales para determinar el estado reproductivo, el sexo y el eventual estrés fisiológico en fauna silvestre tiene un potencial enorme en la generación de conocimiento sobre la ecología y la evolución de vertebrados silvestres, pero también para el planteamiento de esfuerzos de conservación y de manejo de vertebrados. Sin embargo, la endocrinología de campo, como disciplina 
nueva, tiene una posición desventajosa respecto de la endocrinología biomédica que se efectúa en el laboratorio con tamaños de muestra grandes y condiciones controladas. Este campo de investigación requiere aún de ajustes importantes para responder las preguntas que los ecólogos desean responder. Por ejemplo, la identidad del donador de la muestra se desconoce en muchas ocasiones y las muestras que se encuentran en los transectos o los cuadrantes son generalmente viejas y, por lo tanto, han sufrido una modificación de su contenido hormonal.

Debido a la velocidad con las que se realiza investigación en el primer mundo, la estrategia adaptativa a seguir debería ser una alianza de laboratorios e investigadores que se apoyen en términos de material humano excelentemente formado en su área (ya sea la ecología o las técnicas de laboratorio) y de infraestructura, donde las metodologías de laboratorio se mantengan actualizadas y las investigaciones ecológicas que se planeen tengan fundamentos teóricos sólidos. Finalmente, la generación de publicaciones que vayan formando un bagaje de literatura en esta línea de investigación, en que se documenten claramente las variables consideradas y que tengan diseños experimentales adecuados, es imprescindible.

\section{AGRADECIMIENTOS}

Este documento es una evaluación de logros y del trabajo realizado por CV durante los últimos 5 años y hubiera sido imposible sin el esfuerzo en el campo y el laboratorio de los otros 3 autores y sin las numerosas pláticas mantenidas sobre los métodos aplicados y los hallazgos en cada investigación. Sin embargo, ninguna de estas cosas hubiera resultado fructífera sin la interacción con el Dr. Arturo Salame-Méndez de la Universidad Autónoma Metropolitana, Unidad Iztapalapa, quien ha apoyado económica y moralmente investigaciones e ideas. Durante la realización de cada investigación se contó con becas de CONACyT para estudios de posgrado (LEM-R: 163490; LMG-F: 159239; RM-M: 164446). Todos los trabajos efectuados han sido posibles gracias al préstamo de equipo de otros investigadores del INECOL y de otras instituciones. Las extracciones de hormonas de los estudios de LEM-R y RM-M se efectuaron en el Laboratorio de Análisis de Suelos del INECOL a cargo del Dr. Daniel Geissert y con asesoría de Ninfa Portilla y Lourdes Cruz. Las extracciones en el trabajo de LMG-F se llevaron a cabo en el Laboratorio de Fisiología de la Reproducción del Centro de Investigaciones Fisiológicas de la Universidad Autónoma de Tlaxcala con el permiso de la Dra. Margarita Martínez y la ayuda de Leticia Nicolás. Las mediciones de las concentraciones hormonales en el estudio de LEM-R se efectuaron gracias a la donación de kits por parte del Zoológico de St. Louis, Missouri, en el Laboratorio de Procesos Médicos Especializados con ayuda del técnico Tomás Domínguez. La medición de hormonas del trabajo de LMG-F y el de RM-M fue efectuada en el Laboratorio de Neurofisiología de la Universidad Autónoma de Querétaro gracias a la autorización del Dr. Marco Antonio Sánchez y la ayuda de Carlos Chávez. Las extracciones de ADN en el proyecto de CV y Antonio Guillén se están efectuando en el Laboratorio de Biología Molecular del INECOL a cargo del Dr. Alejandro Espinosa de los Monteros y con el trabajo personal del Dr. Antonio Guillén. 
Valdespino et al.: Metodologías no invasivas para estudiar vertebrados

\section{LITERATURA CITADA}

Adlercreutz, H. \& F. Martin. 1980. Biliary excretion and intestinal metabolism of progesterone and estrogens in man. J. Steroid. Biochem. 13: 231-244.

Allendorf, F.W. \& R.F. Leary. 1986 Heterozygosity and fitness in natural populations of animals. Pp. 57-76. En: Fiedler, P.L. \& S.K. Jain (Eds.). Conservation Biology: the theory and practice of nature conservation preservation and management. Chapman \& Hall. Nueva York, EUA.

Aranda, M. 2000. Huellas y otros rastros de los mamíferos grandes y medianos de México. Conabio-Instituto de Ecología, A.C. 212 pp.

Aranyi, P. 1983. Activation and Deactivation of the Glucocorticoid Hormone-Receptor Complex. Eur. J. Biochem. 129: 549-554

Asa, C.S. 1996. Reproductive physiology. Pp. 390-417. En: Kleiman, D.G., M.E. Allen, K.V. Thompson \& S. Lumpkin (Eds.) Wild mammals in captivity. Chicago Press. Chicago, EUA.

1997. Hormonal and experiential factors in the expression of social and parental behavior in canids. Pp. 129-149. En: Solomon, N.G. \& J.A. French (Eds.). Cooperative Breeding in Mammals. Cambridge Univ. Press. Cambridge, EUA.

Axelrod, J. \& T.D. Reisine. 1984. Stress hormones: their interaction and regulation. Science 224: 452-459.

Ayala-Cano, S.G. 2003. Estrés fisiológico relacionado con la dinámica reproductiva del borrego cimarrón, Ovis canadensis cremnobates, en la Sierra San Pedro Mártir, Baja California, México. Tesis de Maestría en Manejo de Ecosistemas de Zonas Áridas. Facultad de Ciencias. UABC Campus Ensenada, México. 159 pp.

Ayala-Cano, S.G. \& R. Martínez-Gallardo. 2001. Development of a methodology to determine steroid hormone levels $\left(\mathrm{P}_{4}, \mathrm{~T}, \mathrm{E}_{2}\right)$ of bighorn sheep (Ovis canadensis cremnobates) pellet group in the San Pedro Martir Sierra, Baja California, Mexico. Desert Bighorn Council Transactions 45: 173-189.

Ball, J.P., G. Ericsson \& K. Wallin. 1997. Climate changes, moose and their human predators. Ecol. Bull. 47:178-187.

Ballou, J.D. \& T.J. Foose. 1996. Demographic and genetic management of captive populations. Pp. 263-283. En: Kleiman, D.G., M.E. Allen, K.V. Thompson \& S. Lumpkin (Eds.) Wild mammals in captivity. Chicago Press. Chicago, EUA.

Bateson, P. \& E.L. Bradshaw. 1997. Physiological effects of hunting red deer (Cervus elaphus). Proc. R. Soc. London B 264: 1707-1714.

Beach, F. 1976. Sexual attractivity, proceptivity, and receptivity in female mammals. Horm. Behav. 7: 105-138

Bercovitz, A.B., N.M. Czekala \& B. Lasley. 1978. A new method of sex determination in monomorphic birds. J. Zoo Anim. Med. 9 (4): 114-124.

Berger, J., J.W. Testa, T. Roffe \& S.L. Monfort. 1999. Conservation endocrinology: a noninvasive tool to understand relationships between carnivore colonization and ecological carrying capacity. Cons. Biol. 13(5): 980-989. 
Bishop, C.M. \& M.R. Hall. 1991. Non-invasive monitoring of avian reproduction by simplified faecal steroid analysis. J. Zool., London 224: 649-668.

Bookhout, T.A. 1996. Research and Management Techniques for Wildlife and Hábitats. Wildlife Society. Maryland, EUA. 1256 pp.

Broom, D.M. 1988. The scientific assessment of animal welfare. Appl. Anim. Behav. Sci. 20: 5-19.

Bronson, F.H. \& P.D. Heideman. 1994. Seasonal regulation of reproduction in mammals. Pp. 541-583. En: E. Knobil \& J.D. Neill (Eds.). The Physiology of Reproduction. Raven Press Ltd. Nueva York, EUA.

Brousset Hernández-Jáuregui, D.M., F. Galindo Maldonado, R.A. Valdez Pérez, M. Romano Pardo \& A. Schuneman de Aluja. 2005. Cortisol en saliva, orina y heces: evaluación no invasiva en mamíferos silvestres. Vet. Méx. 36 (3): 325-337.

Brown, R.E. 1985. Hormones and Parental Behavior in Vertebrates. Am. Zool. 25: 895-910

Buchanan, K.L. \& A.R. Goldsmith. 2004. Noninvasive endocrine data for behavioural studies: the importance of validation. Anim. Behav. 67: 183-185.

Buenrostro, A., S. Gallina \& G. Sánchez-Rojas. 2004. Diferencias en la calidad de la dieta de venado cola-blanca (Odocoileus virginianus mexicanus) determinadas por concentraciones de nitrógeno fecal. XXI Simposio sobre Fauna Silvestre "Gral. MV Manuel Cabrera Valtierra", del 24-26 de nov. 2004. Colima Col. Fac. Medicina Veterinaria y Zootecnia-UNAM.

Buiter, R.M., W. Schaftenaar \& S.J. Dieleman. 1992. Application of faecal steroid analysis to several zoo animals in The Netherlands and Belgium. Pp. 21-24. En: Schaftenaar, W., R.M. Buiter \& S.J. Dieleman (Eds.). The first international symposium on faecal steroid monitoring in zoo animals. Royal Rotterdam Zoological and Botanical Gardens. Holanda.

Campbell, C.J., S.E. Shideler, H.E. Todd \& B.L. Lasley. 2001. Fecal analysis of ovarian cycles in female black-handed spider monkeys (Ateles geoffroyi). Am. J. Primatol. 54: 79-89.

Carlstead, K. 1996. Effects of captivity on the behavior of wild mammals. Pp. 317-333. En: Kleiman, D.G., M.E. Allen, K.V. Thompson \& S. Lumpkin (Eds.) Wild mammals in captivity. Chicago Press. Chicago, EUA.

Carlstead, K., J.L. Brown \& W. Strawn. 1993. Behavioral and physiological correlates of stress in laboratory cats. Appl. Anim. Behav. Sci. 38:143-158.

Cerda-Molina, A. L., Hernández-López, D. L., Paéz-Ponce, S. Rojas-Maya \& R. Mondragón-Ceballos. 2006. Seasonal variations of fecal progesterona and 17 $\alpha$-estradiol in captive female black-handed spinder monkeys (Ateles geoffroyi). Theriogenology 66:1985-1993

Cockrem, J.E. \& J.R. Rounce. 1994. Faecal measurements of oestradiol and testosterone allow the non-invasive estimation on plasma steroid concentrations in the domestic fowl. British Poultry Sci. 35: 433-443.

Cockrem, J.E. \& P.J. Sedon. 1994. Annual cycle of sex steroids in the yellow-eyed penguin (Megadyptes antipodes) on south island, New Zealand. Gen. Comp. Endocrin. 94: 113-121.

Cooperrider, A.Y. 1986. Food habits. Pp. 699-710. En: Cooperrider, A.Y., R.J. Boyd \& H.R. Stuart (Eds.). Inventory and monitoring of wildlife hábitat. U.S. Department of the Interior-Bureau of Land Management. Colorado, EUA. 
Valdespino et al.: Metodologías no invasivas para estudiar vertebrados

Creel, S. 2005. Dominance, aggression, and glucocorticoid levels in social carnivores. $J$. Mammal. 86(2): 255-264.

Creel, S., J.E. Fox, A. Hardy, J. Sands, B. Garrott \& R.O. Peterson. 2002. Snowmobile activity and glucocorticoid stress responses in wolves and elk. Cons. Biol. 16: 809-814.

Cummings, D.C., M.E. Quigley \& S.S. Yen. 1983. Acute suppression of circulating testosterone levels by cortisol in men. J. Clinic Endocrin. Metabol. 57: 671-673.

Davis, D.E. \& R.L. Winstead. 1980. Estimating the numbers of wildlife populations. Pp. 221-246. En: Schemnitz, S.D. (Ed.). Wildlife management techniques manual. The Wildlife Society. Washington, D.C. EUA.

Davison, A., J.D. Birks, R.C. Brookes, T.C. Braithwaite \& J.E. Messenger. 2002. On the origin of faeces: morphological versus molecular methods for surveying rare carnivores from their scats. Zool. Soc. London 257: 141-143.

Dloniak, S.M.; J.A. French, N.J. Place, M.L. Weldele, S.E. Glickman \& K.E. Holekamp. 2004. Non-invasive monitoring of fecal androgens in spotted hyenas (Crocuta crocuta) Gen. Comp. Endocrin. 135: 51-61.

Dobson, H. \& R.F. Smith 2000. What is stress, and how does it affect reproduction? Anim. Reprod. Sci. 60-61: 743-752.

Elbroch, M. 2003. Mammal Tracks \& Sign: A Guide to North American Species Stackpole Books Pensilvania EUA 779 pp

Ezan, E., E. Laplante, M.T. Bluet-Pajot, F. Mounier, S. Mamas, D. Grouselle, J.M. Grognet \& C. Kordon. 1997. An enzyme immunoassay for rat growth hormone: validation and application to the determination of plasma levels and in vitro release. $J$. Immunoassay 18 (4): 335-356.

Ezcurra, E. \& S. Gallina. 1981. Biology and populations dynamics of white-tailed deer in northwestern Mexico. Pp. 77-108. En: Ffolliot P. F. \& S. Gallina (Eds.). Deer biology, hábitat requirements, and management in western North America. Instituto de Ecologia, A. C. México.

Farner, D.S. \& J.C. Wingfield. 1980. Reproductive endocrinology of birds. Ann. Rev. Physiol. 42: 457-472.

Ferin M. 1999. Stress and the reproductive cycle. J. Clin. Endocrinol. Metab. 84: 1768-1774.

Foley, C.A.H., S. Papageroge \& S.K. Wasser. 2001. Noninvasive stress and reproductive measure of social and ecological pressures in free-ranging African elephants. Cons. Biol. 15 (4): 1134-1142.

García-Feria, L.M. 2003. Medición de esteroides fecales para la determinación del sexo y condición reproductiva del pavón (Oreophasis derbianus, Gray 1844) en cautiverio. Tesis de Maestría de Manejo de Fauna Silvestre. Instituto de Ecología, A.C. 85 pp.

González-García, F. 1984. Aspectos biológicos del pavón Oreophasis derbianus G.R. Gray (Aves: Cracidae) en la reserva natural El Triunfo, Municipio de Angel Albino Corzo, Chiapas, México. Tesis de Licenciatura, Univ. Veracruzana. Facultad de Biología. Veracruz, México. 
González-Trápaga, R. \& G. Aguirre. 2000. Sex-steroids associated with the reproductive cycle in male and female Bolson tortoise, Gopherus flavomarginatus. Acta Zool. Mex. (n.s.) 80: 101-117.

Gower, D.B. 1979. Steroid hormones. Croom Helm. Londres, Inglaterra. 455 pp.

Goymann, W. 2005. Noninvasive monitoring of hormones in bird droppings: physiological validations, sampling, extraction, sex differences, and the influence of diet on hormone metabolite levels. Ann. N.Y. Acad. Sci. 1046: 35-53.

Goyman, W, E. Möstl, T.V. Hof, M.L. East \& H. Hofer. 1999. Noninvasive fecal monitoring of glucocorticoids in spotted hyenas, Crocuta crocuta. Gen. Comp. Endocrin. 114: 340-348.

Graham, L.H., K.L. Goodrowe, J.I. Raeside \& R.M. Liptrap. 1995. Non-invasive monitoring of ovarian function in several felid species by measurement of fecal stradiol17? and progestins. Zoo Biol. 14: 223-237.

Graham, S. 1996. Issues of surplus animals. Pp. 290-296. En: Kleiman, D.G., M.E. Allen, K.V. Thompson \& S. Lumpkin (Eds.) Wild mammals in captivity. Chicago Press. Chicago, EUA.

Griffin, J.E. \& S.R. Ojeda. 1988. Endocrine physiology. Oxford Univ. Press. Nueva York, EUA. 367 pp.

Gross, T.S. 1992. Development and use of faecal steroid analyses in several carnivore species. Pp. 55-61. En: Schaftenaar, W., R.M. Buiter \& S.J. Dieleman (Eds.). The first international symposium on faecal steroid monitoring in zoo animals. Royal Rotterdam Zoological and Botanical Gardens, Holanda.

Halfpenny, J.C. \& E.A. Biesiot. 1986. Field guide to mammal tracking in North America. Johnson Printing Co. Colorado, EUA. 158 pp.

Harlow, H. J., F. G. Lindzey, W. D. V. Sickle \& W. A. Gern. 1992. Stress response of cougars to nonlethal pursuit by hunters. Can. J. Zool. 70: 136-139.

Harper, J.M. \& S.N. Austad. 2000. Fecal glucocorticoids: a noninvasive method of measuring adrenal activity in wild and captive rodents. Phys. Biochem. Zool. 73 (1): 12-22.

Harris, L.D. \& G. Silva-López. Forest fragmentation and the conservation of biological diversity. Pp. 197-238. En: Fiedler, P.L. \& S.K. Jain (Eds.). Conservation Biology: the theory and practice of nature conservation preservation and management. Chapman \& Hall. Nueva York, EUA.

Hegner, R.E. \& J.C. Wingfield. 1987. Effects of experimental manipulation of testosterone levels on parental investment and breeding success in male house sparrows. Auk 104: 462

Heistermann, M.; E. Möstl \& J.K. Hodges. 1995. Non-invasive endocrine monitoring of female reproductive status: methods and applications to captive breeding and conservation of exotic species. Pp. 36-48. En: Gauslophe, A., J.K. Hodges, W. Kaumanns (Eds.) Research and captive propagation. Filander Verlag Gmbh Erlanger. Finlandia.

Heistermann, M., R. Palme \& A. Ganswindt. 2006. Comparison of Different Enzymoimmunoassays for Assessment of Adrenocortical Activity in Primates Based on Fecal Analysis. Am. J. Primatol. 68: 257-273. 
Hennessy, M.B., J.P. Heybach, J. Vernikos \& S. Levine. 1979. Plasma corticosterone concentrations sensitively reflect levels of stimulus intensity in the rat. Physiol. Behav. 22: 821-825.

Herman, J.P. \& W.E. Cullinam. 1997. Neurocircuitry of stress: central control of the hypothalamo-pituitary-adrenocortical axis. Trends Neurosci. 20: 78-84.

Hirayama, K. 1989 The fecal flora of the giant panda J. Appl. Bacteriol. 67: 411-415

Hirschenhauser, K., E. Mostl \& K. Kotrschal. 1999. Seasonal patterns of sex steroids determined from feces in different social categories of greylag geese (Anser anser). Gen. Comp. Endocrin. 114: 67-79.

Hodges, J.K. 1996. Determining and manipulating female reproductive parameters. Pp. 418428. En: Kleiman, D.G., M.E. Allen, K.V. Thompson \& S. Lumpkin (Eds.) Wild mammals in captivity. Chicago Press. Chicago, EUA.

Johnson, A.L. \& A. van Tienhoven. 1980. Plasma concentrations of six steroids and LH during the ovulatory cycle of the hen, Gallus domesticus. Biol. Reprod. 23: 286-393.

Judd, H.L., J.P. Bacon, D. Rüedi, V. Girard \& K. Benirschke. 1977. Determination of sex in the Komodo dragon (Varanus komodoensis). Int. Zoo Yrbk. 17: 208-210.

Ketterson, E. \& V. Nolan-Jr. 1992. Hormones and life histories: an integrative approach. Am. Nat. 140: S33-S62

Ketterson, E.D., V.J. Nolan, L. Wolf, C. Ziegenfus, A.M. Dufty, Jr., G.F. Ball \& T.S. Johnsen. 1991. Testosterone and avian life histories: the effect of experimentally elevated testosterone on corticosterone and body mass in dark-eyed juncos. Horm. Behav. 25: 489503

Khan, M.Z., J. Altmann, S.S. Isani \& J. Yu. 2002 A matter of time: evaluating the storage of fecal samples for steroid analysis. Gen. Comp. Endocrin. 128: 57-64

Kirkpatrick, J.F., S.E. Shiedeler, B.L. Lasley, J.W. Turner, Jr. \& N.M. Czekala. 1992. Field application of faecal steroid monitoring to free-ranging wildlife. Pp. 25-34. En: Schaftenaar, W., R.M. Buiter \& S.J. Dieleman (Eds.). The first international symposium on faecal steroid monitoring in zoo animals. Royal Rotterdam Zoological and Botanical Gardens, Holanda.

Knol, B.W. 1991. Stress and the endocrine hypothalamus-pituitary-testis systems: a review. Vet. Quart. 13: 104-114.

Kohn, M.H. \& R.K. Wayne. 1997. Facts from feces revisited. TREE 12: 223-227

Korschgen, L.J. 1980. Procedures for food habits analysis. Pp. 113-128. En: Schemnitz, S.D. (Ed.). Wildlife management techniques manual. The Wildlife Society. Washington, D.C. EUA.

Lacy, R.C. 1992. The effects of inbreeding on isolated populations: are minimum viable populations sizes predictable? Pp. 277-296. En: Fiedler, P.L. \& S.K. Jain (Eds.). Conservation Biology: the theory and practice of nature conservation preservation and management. Chapman \& Hall. Nueva York, EUA.

Lance, V. \& I.P. Callard. 1978. Hormonal control of ovarian steroidogenesis in nonmammalian vertebrates. Pp. 361-407. En: R.E. Jones (Ed.). The vertebrate ovary. Plenum Press. Nueva York, EUA. 
Lancia, R.A., J.D. Nichols \& K.H. Pollock. 1996. Estimating the number of animals in wildlife populations. Pp. 215-253. En: Bookhout, T.A. (Ed.). Research and Management Techniques for Wildlife and Hábitats. Wildlife Society. Maryland, EUA.

Landsman, T. \& D.J. Waxman. 2005. Role of the Cytokine-induced SH2 Domaincontaining Protein CIS in Growth Hormone Receptor Internalization. J. Biol. Chem. 280 (45): 471-480.

Lasley, B.L. 1985. Methods for evaluating reproductive function in exotic species. Adv. Vet. Sci. Comp. Med. 30: 209-228.

Lasley, B.L. \& J.F. Kirkpatrick. 1991. Monitoring ovarian function in captive and freeranging wildlife by means of urinary and fecal steroids. J. Zool. Wildl. Med. 22: 23-31.

Laurance, W.F. \& R.O. Bierregaard, Jr. 1997. A crisis in the making. Pp. xi-xv. En: Laurance, W.F. \& R.,O. Bierregaard, Jr. (Eds.). Tropical forest remmants. The University of Chicago Press. Chicago, EUA.

Lawton, J.H., D.E. Bignell, B. Bolton, G.F. Bloemers, P. Eggleton, P.M. Hammond, M. Hodda, R.D. Holt, T.B. Larsenk, N.A. Mawdsley, N.E. Stork, D.S. Srivastava \& A.D. Watt. 1998. Biodiversity inventories, indicator taxa and effects of hábitat modification in tropical forest. Nature 391: 72-76.

Lee, J., L. Tell \& B. Lasley. 1999. A comparison of sex steroid hormone excretion and metabolism by Psittacine species. Zoo Biol. 18: 247-260.

Licht, P. 1984. Reptiles. Pp. 206-282. En: G.E. Lamming (Ed.). Marshall's physiology of reproduction. Vol. 1. Churchill Livingstone. Edinburgh, Inglaterra.

Litvaitis, J.A. K. Titus \& E.M. Andersen. 1996. Measuring vertebrate use of terrestrial hábitats and foods. Pp. 254-274. En: Bookhout, T.A. (Ed.). Research and Management Techniques for Wildlife and Hábitats. Wildlife Society. Maryland, EUA.

Lombardi, J. 1998. Comparative Vertebrate Reproduction. Kluwer Academic Publishers. Boston, EUA. 439 pp.

Loskutoff, N.M., J.E. Ott \& B.L. Lasley. 1983. Strategies for assessing ovarian function in exotic species. J. Zoo Anim. Med. 14: 3-12.

Lynch, J.W., M.Z. Khan, J. Altmann, M.N. Njahira \& N. Rubenstein. 2003. Concentrations of four fecal steroids in wild baboons: short-term storage conditions and consequences for data interpretation. Gen. Comp. Endocrin. 132: 264-271.

Mandujano, S. Y S. Gallina. 1995. Comparison of deer censusing methods in tropical dry forest. Wildlife Soc. B. 23 (2): 180-186.

Martínez-Mota, R. 2004. Comparación de cortisol fecal de monos aulladores (Alouatta pigra) que habitan un bosque fragmentado y uno continuo como medida para determinar estrés. Tesis de Maestría de Manejo de Fauna Silvestre. Instituto de Ecología, A.C. 85 pp.

Martínez-Mota, R., C. Valdespino, M. A. Sánchez-Ramos \& J. C. Serio-Silva. 2007. Effects of forest fragmentation on the physiological stress response of black howler monkeys. Anim. Cons. 10: 374-379.

Martínez-Romero, L.E. 2004. Determinación de fechas de aprovechamiento del venado cola blanca (Odocoileus virginianus) a través de hormonas sexuales y comportamiento. Tesis de Maestría de Manejo de Fauna Silvestre. Instituto de Ecología, A.C. 77 pp. 
Mason, C.F. \& J.R. Ratford. 1994. PCB congeners in tissues of European otter (Lutra lutra). Bull. Environ. Contam. Toxicol. 53: 548-554.

McDougall, L. 1992. The complete tracker. The Lyons Press. Nueva York, EUA. 273pp

McEwen, B.S. \& R.M. Sapolsky. 1995. Stress and cognitive function. Curr. Opin. Neurobiol. 5: 205-216.

McNabb, F.M.A. 2004. Reprint of "Avian thyroid development and adaptive plasticity" Gen. Comp. Endocrinol. 147: 93-101.

Menkhorst, P. \& F. Knight. 2001. A Field guide to the mammals of Australia Oxford University Press. Melbourne, Australia. 269pp

Mercado-Reyes, M., S.E. Ramos-Solís, M. Blancas-Mosqueda, C. Mondragón-de la Peña \& J.P. Tavizón-García. 2001. Concentración de progesterona en heces fecales de hembra de venado cola blanca (Odocoileus virginianus) durante el ciclo reproductivo en cautiverio. 5as. Jornadas de Investigación. 25-29 junio 2001 Universidad Autónoma de Zacatecas: 1-10.

Mills, M.G.L. 1996. Methodological advances in capture, census, and food-habits studies of large African carnivores. Pp. 223-242. En: J.L. Gittleman (Ed). Carnivore behavior, ecology and evolution (vol. 2). Cornell Univ. Press. Nueva York, EUA.

Millspaugh, J.J., R.J. Woods, K.E. Hunt, K.J. Raedeke, G.C. Brundige, B.E. Washburn, \& S.K. Wasser. 2001. Using fecal glucocorticoid assays to study the physiological stress response of elk. Wildlife Soc. B. 29: 899-907.

Millspaugh, J.J., B.E. Washburn, M.A. Milanick, J. Beringer, L.P. Hansen \& T.M. Meyer, 2002. Noninvasive techniques for stress assessment in white-tailed deer. Wildlife Soc. B. 30: 899-907.

Monfort, S.L., C.C. Schwartz \& S.K. Wasser. 1993. Monitoring reproduction in captive moose using urinary and fecal steroid metabolites. J. Wildl. Manage. 57 (2): 400-407.

Monfort, S.L., S.K. Wasser, K.L. Mashburn, M. Burke, B.A. Brewer \& S.R. Creel. 1997. Steroid metabolism and validation of noninvasive endocrine monitoring in the African wild dog (Lycaon pictus). Zoo Biol. 16: 533-548.

Montes-Pérez, R.C., P. Cervera-Hernández \& F. Victoria-Arceo. 1999. Diagnóstico de gestación en venadas cola blanca (Odocoileus virginianus) a través de la medición de metabolitos de progestinas fecales. XVI Congreso de la Asociación de Zoológicos, Criaderos y Aviarios de la República Mexicana. Guadalajara, Jalisco.

Morgan, D., K.A. Grant, O.A. Prioleau, S.H. Nader, J.R. Kaplan \& M.A. Nader. 2000. Predictors of social status in Cynomolgus monkeys (Macaca fascicularis) after group formation. Am. J. Primatol. 52: 115-131.

Möstl, E. 1992. Measuring steroids in faeces of mammals to monitor the reproductive status: success and disappointment. Pp. 5-9. En: Schaftenaar, W., R.M. Buiter \& S.J. Dieleman (Eds.). The first international symposium on faecal steroid monitoring in zoo animals. Royal Rotterdam Zoological and Botanical Gardens, Holanda.

Möstl, E. \& R. Palme, 2002. Hormones as indicators of stress. Domest. Anim. Endocrin. 23: 67-74 (Número especial).

Munck A., P.M. Guyre, N.J. Holbrook. 1984. Physiological functions of glucocorticoids in stress and their relation to pharmacological actions. Endocrinol. Rev. 5: 25-44. 
Myers, N. 1988. Tropical forests and their species, going, going...Pp. 28-35. En: Wilson, E.O. Biodiversity. National Academy Press. Washington, EUA.

Nelson, R.J. 2000. An introduction to behavioral endocrinology. Sinauer Ass. Inc. Pub. Massachusetts, EUA. 724 pp.

Nogueira, G.P \& J.C.R. Silva. 1997. Plasma cortisol levesl in captive wild felines after chemical restraint. Brazilian J. Med. Biol. Res. 30: 1359-1361.

Norcross, J.L. \& J.D. Newman. 1999. Effects of separation and novelty on distress vocalizations and cortisol in the common marmoset (Callithrix jacchus). Am. J. Primatol. 47: 209-222.

Norman, A.W. \& G. Litwack. 1987. Hormones. Acad. Press. Orlando, EUA. 345 pp.

Ohl, F. \& E. Fuchs. 1999. Differential effects of chronic stress and memory processes in the tree shrew. Brain. Res. Cogn. Brain. Res. 7: 379-387.

Ortiz-Martínez, T., S. Gallina, M. Briones-Salas \& G. González. 2005. Densidad poblacional y caracterización del hábitat del venado cola blanca (Odocoileus virginianus oaxacensis, Goldman y Kellog, 1940) en un bosque templado de la sierra norte de Oaxaca, Mexico. Acta Zool. Mex. (n.s.) 21(3): 65-78.

Paxinos, E., C. Mcintosh, K. Ralls \& R. Fleischer. 1997. A noninvasive method for distinguishing among canid species: amplification and enzyme restriction of DNA from dung. Mol. Ecol. 6: 483-486.

Pérez-García, L. 2005. Determinación de estrés fisiológico en borrego cimarrón (Ovis canadensis) relacionado con el manejo extensivo en Sonora y en Baja California Sur, México. Tesis de Maestría en Manejo de Ecosistemas de Zonas Áridas. Facultad de Ciencias. UABC Campus Ensenada, México. 102 pp.

Pérez-Mejía, S., S. Mandujano \& L.E. Martínez-Romero. 2004. Tasa de defecación del venado cola blanca, Odocoileus virginianus mexicanus, en cautiverio en Puebla, México. Acta Zool. Mex. (ns): 167-170.

Peter, A.T., J.K. Critser \& N. Kapustin. 1996. Analysis of sex steroid metabolites excreted in the feces and urine of nondomesticated animals. Compendium 18 (7): 781-792.

Phillips, M.K. \& J. Scheck. 1991. Parasitism in captive and reintroduce wolves. J. Wildl. Disease 27: 498-501.

Podestá, E.J. \& M.A. Rivarola. 1974. Concentrarion of androgens in whole testis, seminiferous tabules ans interstitial tissue of rats at different stages of development. Endocrinology 95: 455-461.

Pride, R.E. 2005. Optimal group size and seasonal stress in ring-tailed lémurs (Lemur catta). Behav. Ecol. 16: 550-560.

Putman, R.J. 1984. Facts from feces. Mamm. Rev. 14: 79-97.

Ramenofsky, M. 1984. Agonistic behavior and endogenous plasma hormones in Japanese quail. Anim. Behav. 32: 698-708.

Ray, J.C. \& M.E. Sunquist. 2001. Trophic relations in a community of African rainforest carnivores. Oecologia 127: 395-408.

Reburn, C.J. \& K.E. Wynne-Edwards. 1999. Hormonal changes in males of naturally biparental and uniparental mammal. Horm. Behav. 35: 163-176 
Valdespino et al.: Metodologías no invasivas para estudiar vertebrados

Reeder, D.M \& K.M. Kramer. 2005. Stress in free-ranging mammals: integrating physiology, ecology, and natural history. J. Mamm. 86 (2): 225-235.

Robinson, M.H. 1996. The BioPark concept and the exhibition of mammals. Pp 161-166. En: Kleiman, D.G., M.E. Allen, K.V. Thompson \& S. Lumpkin (Eds.) Wild mammals in captivity. Chicago Press. Chicago, EUA.

Romero, L.M. 2004. Physiological stress in ecology: lessons from biomedical research. TREE 19 (5): 249-255.

Safar-Herman, N., M.N. Ismail, H. Sun Choi, E. Möstl \& E. Bamberg. 1987. Pregnancy diagnosis in zoo animals by estrogen determination in feces. Zoo Biol. 6: 189-193.

Sánchez-Rojas, G. \& S. Gallina. 2000. Mule deer (Odocoileus hemionus) density in a landscape element of the Chihuahuan Desert, Mexico. J. Arid Environ. 44: 357-368.

Sánchez-Rojas, G., S. Gallina \& M. Equihua. 2004. Pellet morphometry as a tool to distinguish age and sex in the mule deer. Zoo Biol. 23: 139-146.

Sapolsky, R.M. 1992. Neuroendocrinology of the stress response. Pp 287-324. En: Becker, J.B., S.M. Breedlove, D. Crews, M.M. McCarthy (Eds.). Behavioral Endocrinology. Massachusetts Institute of Technology Press. Nueva York, EUA.

- 1993. The physiology of dominance in stable versus unstable social hierarchies. Pp. 171-204. En: Mason W.A. \& S.P. Mendoza (Eds.). Primate Social Conflict. Sunny Press. Albany, EUA.

Schaftenaar, W., R.M. Buiter \& S.J. Dieleman. 1992. The first international symposium on faecal steroid monitoring in zoo animals. Royal Rotterdam Zoological and Botanical Gardens, Holanda.

Schwarzenberger, F., E. Möstl, E. Bamberg, J. Pammer \& O. Schemehlik. 1991. Concentrations of progestagens and oestrogens in the faeces of pregnant Lipizzan, Trotter and Thoroughbred mares. J. Reprod. Fert. Supplement 44: 489-499

Seidensticker, J. \& J.G. Doherty. 1996. Integrating animal behavior and exhibit design. Pp. 180-190. En: Kleiman, D.G., M.E. Allen, K.V. Thompson \& S. Lumpkin (Eds.) Wild mammals in captivity. Chicago Press. Chicago, EUA.

Shaw, H.J., D.I. Green, A.W. Sainbury \& W.V. Holt. 1995. Monitoring ovarian function in scimitar-horned oryx (Oryx dammah) by measurment of fecal 20 alfa-progestagen metabolites. Zoo Biol. 14: 239-250.

Shirtcliff, E.A., D.A. Granger \& A. Likos. 2002. Gender differences in the validity of testosterone measured in saliva by immunoassay. Horm. Behav. 42: 62-69.

Siiteri, P.K. 1981. Extraglandular oestrogen formation and serum binding of oestradiol: relationship to cancer. J. Endocrin. 89: 119-129.

Soto, M.A. 2004. Cuantificación de esteroides sexuales y su relación con la conducta reproductiva en el lobo gris mexicano (Canis lupus baileyi). Tesis de maestría en psicobiología. Facultad de Psicología, UNAM

Soto, M. A., A. Salame-Méndez; J. Ramírez-Pulido, L. Yánez \& M. A. Armella. 2004. Valoración de hormonas esteroides en heces de una pareja de lobo mexicano (Canis lupus baileyi) en cautiverio. Acta Zool. Mex. (n.s.) 20(2): 187-196 
Soto-Mendoza, S. 2006. Monitoreo no invasivo de las etapas reproductivas en borregas cimarrón (Ovis canadensis mexicana) en cautiverio mediante la observación conductual reproductiva y la cuantificación de esteroides fecales. Tesis de maestría en producción y salud animal. Facultad de Medicina Veterinaria y Zootecnia. UNAM, México. 68 pp.

Sturkie, P.D. 1968. Avian Physiology. Comstock Publisher Association.

Stratakis, C.A. \& G.P. Chrousos. 1995. Neuroendocrinology and pathophysiology of the stress system. Ann. N.Y. Acad. Sci. 771: 1-18.

Strier, K.B. \& T.E. Ziegler. 1997. Behavioral and endocrine characteristics of the reproductive cycle in wild muriqui monkeys, Brachyteles arachnoids. Am. J. Primatol. 42: 299-310.

Strier, K.B., T.E. Ziegler \& D.J. Wittwer. 1999. Seasonal and social correlates of fecal testosterone and cortisol levels in wild male Muriquis (Brachyteles arachnoides). Horm. Behav. 35: 125-134.

Terao, K., M. Hamano \& Y. Koyama. 1995. The repeated procedure of weaning and peer group formation causes accumulation of stress and changes of plasma cortisol level and natural killer activity in squirrel monkeys (Saimiri sciureus). Primates 36: 121-127.

Tell, L.A. \& B.L. Lasley. 1991. An automated assay for fecal estrogen conjugates in the determination of sex in avian species. Zoo Biol. 10: 361-367.

Tempel, D.J. \& R.J. Gutierresz. 2003. Fecal corticosterone levels in California spotted owls exposed to low-intensity chainsaw sound. Wildl. Soc. Bull. 31 (3): 698-702.

Temple, S.A. 1974. Plasma testosterone titers during the annual reproductive cycle of starlings (Sturnus vulgaris). Gen. Comp. Endocrin. 22: 470-479.

Terio, K.A., S.B. Citino \& J.L. Brown. 1999. Fecal cortisol metabolism analysis for noninvasive monitoring of adrenocortical function in the cheetah (Acinonyx jubatus). $J$. Zoo and Wildl. Med. 30: 484-491.

Thomas, W. \& H. Qian. 2003. Arresting angiotensin type 1 receptors. Trends Endocrin. Met. 14 (3): 130-137.

Touma, C., N. Sachser, E. Mostl \& R. Palme, 2003. Effects of sex and time of day on metabolism and excretion of corticosterone in urine and feces of mice. Gen. Comp. Endocrin. 130: 267-278.

Valdespino, C, C.S. Asa \& J.E. Bauman. 2002. Estrous cycles, copulation, and pregnancy in the Fennec fox (Vulpes zerda). J. Mammal. 83 (1): 99-109.

Velloso, A.L., S.K. Wasser, S.L. Monfort \& J.M. Dietz. 1998. Longitudinal fecal steroid excretion in maned wolves (Chrysocyon brachyurus). Gen. Comp. Endocrin. 112: 96-107.

von der Ohe, C.G. \& C. Servheen. 2002. Measuring stress in mammal using fecal glucocorticoids: opportunities and challenges. Wildlife Soc. B. 30 (4): 1215-1225

von Holst, D. 1998. The concept of stress and its relevance for animal behavior. Adv. Stud. Behav. 27: 1-131.

Wasser, S.K., K. Bevis, G. King \& E. Hanson. 1997. Noninvasive physiological measures of disturbance in the northern spotted owl. Cons. Biol. 11: 1019-1022.

Wasser, S.K., K. Hunt, J. Brown, K. Cooper, C. Crockett, U. Bechert, J. Millespaugh, S. Larson \& S. Monfort. 2000. A generalized fecal glucocorticoid assay for use in a diverse 
array of non-domestic mammalian and avian species. Gen. Comp. Endocrin. 120: 260275.

Wasser, S.K., S.L. Monfort \& D.E. Wildt. 1991. Rapid extraction of faecal steroids for measuring reproductive cyclicity and early pregnancy in free-ranging yellow baboons (Papio cynocephalus cynocephalus). J. Reprod. Fert. 92: 415-423.

Wasser, S.K., L. Risler \& R. Steiner. 1988. Excreted steroids in primate feces over the menstrual cycle and pregnancy. Biol. Reprod. 55: 393-399.

Wasser, S.K., R.I. Thomas, P.P. Nair, S.L. Monfort \& D.E. Wildt. 1992. Effect of diet on fecal steroid measurements. Pp. 10-19. En: Schaftenaar, W., R.M. Buiter \& S.J. Dieleman (Eds.). The first international symposium on faecal steroid monitoring in zoo animals. Royal Rotterdam Zoological and Botanical Gardens, Holanda.

Wynne-Edwards, K.E. \& C.J. Reburn. 2000. Behavioral endocrinology of mammalian fatherhood. TREE 15: 464-468

Wielebnowski, N.C., N. Fletchall, K. Carlstead, J.M. Busso \& J.L. Brown. 2000. Noninvasive assessment of adrenal activity associated with husbandry and behavioural factors in the North American clouded leopard population. Zoo Biol. 21: 77-98.

Wilcove, D.S., C.H. McLellan \& A.P. Dobson. 1986. Hábitat fragmentation in the temperate zone. Pp. 237-256. En: Soulé, M.E. (Ed.) Conservation Biology: the science of scarcity and diversity. Sinauer Assoc. Inc. Pub. Massachusetts, EUA.

Wildt, D.E. 1996. Male reproduction: assessment, management and control of fertility. Pp. 429-450. En: Kleiman, D.G., M.E. Allen, K.V. Thompson \& S. Lumpkin (Eds.) Wild mammals in captivity. Chicago Press. Chicago, EUA.

Wilson, G.J. \& R.J. Delahay. 2001. A review of methods to estimate the abundance of terrestrial carnivores using field signs and observation. Wildl. Res. 28: 151-164.

Wingfield, J.C., K. Hunt, C. Breuner, K. Dunlap, G.S. Fowler, L. Freed \& J. Lepson. 1997. Environmental stress, field endocrinology, and conservation biology. Pp. 95-131. En: Buchholz, J.R. \& R. Clemmons (Eds.). Behavioral Approaches to Conservation in the Wild. Cambridge Univ. Press. Cambridge, EUA.

Wingfield, J.C. \& P. Marler. 1988. Endocrine basis of communication: reproduction and aggression. Pp. 1647-1677. En: Knobil E. \& J.D. Neill (Eds.). The physiology of reproduction. Raven. Nueva York, EUA.

Wingfield, J.C. \& R.M. Sapolsky. 2003. Reproduction and resistance to stress: when and how. J. Neuroendocrinol. 15: 711-724.

Whitten, P.L., R. Stavinsky, F. Aureli \& E. Rusell. 1998. Response of fecal cortisol to stress in captive chimpanzees (Pan troglodytes). Am. J. Primatol. 44: 57-69.

Ziegler, T.E., G. Scheffler \& C.T. Snowdon. 1995. The relationship of cortisol levels to social environment and reproductive functioning in female cotton-top tamarins, Saguinus oedipus. Horm. Behav. 29: 407-424. 